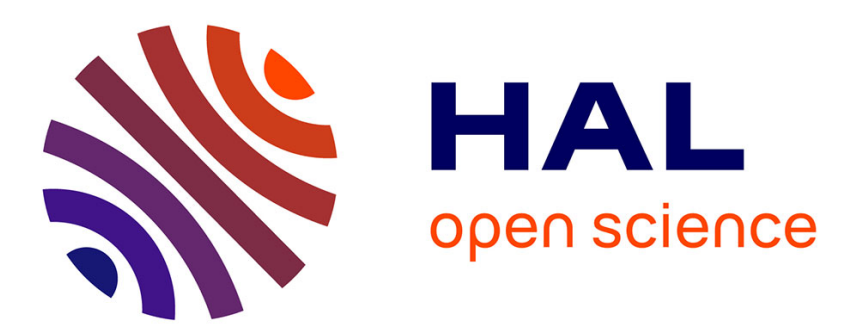

\title{
Assessment of the refined sinus plate finite element: free edge effect and Meyer-Piening sandwich test.
}

\author{
P. Vidal, O. Polit, M. d'Ottavio, E. Valot
}

\section{To cite this version:}

P. Vidal, O. Polit, M. d'Ottavio, E. Valot. Assessment of the refined sinus plate finite element: free edge effect and Meyer-Piening sandwich test.. Finite Elements in Analysis and Design, 2014, 92, pp.60-71. 10.1016/j.finel.2014.08.004 . hal-01366962

\section{HAL Id: hal-01366962 \\ https://hal.science/hal-01366962}

Submitted on 8 Jan 2018

HAL is a multi-disciplinary open access archive for the deposit and dissemination of scientific research documents, whether they are published or not. The documents may come from teaching and research institutions in France or abroad, or from public or private research centers.
L'archive ouverte pluridisciplinaire HAL, est destinée au dépôt et à la diffusion de documents scientifiques de niveau recherche, publiés ou non, émanant des établissements d'enseignement et de recherche français ou étrangers, des laboratoires publics ou privés. 


\title{
Assessment of the refined sinus plate finite element: Free edge effect and Meyer-Piening sandwich test
}

\author{
P. Vidal*, O. Polit, M. D'Ottavio, E. Valot \\ LEME EA 4416, Université Paris Ouest, 50 rue de Sèvres, 92410 Ville d'Avray, France
}

\begin{abstract}
A B S T R A C T
This paper deals with the assessment of a refined sinus model for multilayered composite plates in the framework of severe test cases to highlight the interest and limitations of such an approach. The present sinus model is enriched by higher-order terms for both in-plane and transverse displacements, and layer refinement. This kinematics allows us to exactly ensure both (i) the continuity conditions for displacements and transverse shear stresses at the interfaces between layers of a laminated structure, and (ii) the traction-free conditions at the upper and lower surfaces of the plates. The number of unknowns is independent of the number of layers. A $C^{1}$ 6-node triangular finite element implementation is proposed, which does not suffer any numerical pathologies.

First, the present approach is assessed on its capability to capture the steep transverse stress gradients occurring in the vicinity of free edges and is also compared with models available in the literature. Then, a highly anisotropic sandwich structure proposed by Meyer-Piening is also addressed for further comparison.
\end{abstract}

\section{Introduction}

Composite and sandwich structures are widely used in the weight-sensitive industrial applications due to their excellent mechanical properties, especially their high specific stiffness and strength. In this context, they can be subjected to severe mechanical loading. For composite design, accurate knowledge of displacements and stresses is required. So, it is important to take into account effects of the transverse shear deformation due to the low ratio of transverse shear modulus to axial modulus, or failure due to delamination. In fact, they can play an important role on the behavior of structures in services, which leads to evaluate precisely their influence on local stress fields in each layer, particularly at the interface between layers.

The aim of this paper is to assess the refined sinus model including a higher-order expansion with respect to its capability to capture local effects for laminated and sandwich structures.

It is nowadays well established that theoretical models for heterogeneous structures can be classified as follows:

- the Equivalent Single Layer Models (ESLM), where the classical Love-Kirchhoff (CLT) and Reissner-Mindlin (FSDT) models can be

\footnotetext{
* Corresponding author.

E-mail address: philippe.vidal@u-paris10.fr (P. Vidal).
}

found for plates. The first one leads to inaccurate results for composites because both transverse and normal strains are neglected. The second one where only the transverse normal strain is neglected, needs a shear correction factor. So, the higher order shear deformation theory has been developed (see the work of Reddy [1]), but transverse shear and normal stress continuity conditions at the interfaces between layers are violated. In the ESLM context, a simple way to improve the estimation of the mechanical quantities has been proposed by Murakami [2]: one function is added in each in-plane displacement to introduce the slope discontinuity at the interface between two adjacent layers. It allows us to describe the so-called zig-zag effect.

- the Layer-Wise Models (LWM) that aim at overcoming the restriction of the ESL concerning the discontinuity of out-ofplane stresses at the interface between adjacent layers. The reader can refer to the works of Pagano [3] and Reddy [4].

According to Reddy [5], the number of unknowns remains independent of the number of constitutive layers in the ESLM, while the same set of variables is used in each layer for the LWM.

Another way for obtaining new models is based on the introduction of interface conditions into higher-order model pertaining to the ESLM or to the LWM. This permits us to reduce the number of unknowns and can be viewed as a ZigZag model. Excellent reviews have been made in the following 
articles [6-9] or in the most recent review proposed by Zhang and Yang [10].

It is known that relevant transverse stresses arise in the presence of in-plane stress gradients and in the vicinity of material and/or geometric discontinuities. Free-edge effects are typical boundary layer effects where a 3D stress concentration is locally confined in a small region in the vicinity of the free edge [11]. The free-edge effect arising in a composite plate subjected to tensile loads has been extensively studied since the seminal works of Pipes and Pagano [12,13]. We also note the test case introduced by Meyer-Piening [14] where a highly anisotropic non-symmetric sandwich structure is submitted to a localized pressure. These two configurations can be considered as representative test cases allowing to discriminate 2D models.

Since an exhaustive review is out of the scope of the present investigation, we refer the interested reader to the more complete surveys of this topic by Mittelstedt and Becker [15,16] and focus only on the works related to the Pipes-Pagno tests in the following.

Except the first numerical analysis of the Pipes-Pagano problem provided in [12], which is based on a Finite Difference scheme and the work of Tahani and Nosier [17] based on a semianalytical approach, most of the numerical reference solutions have been obtained by means of the Finite Element Method (FEM). Wang and Crossman employed generalized plane strain, threenode triangular elements for discretizing the mid-section $x_{1}=0$ (axis notation according to Fig. 5) of the laminate [18]. Other approaches are based on the quasi-3D model (Q3D) which refers to the hypothesis of zero gradients along the axial coordinate $x_{1}$ and retaining an axial warping of the $\left(x_{2}, z\right)$-planes which depends only on $x_{2}$ and $z$. We can mention the works of $[19,20]$. Note also the 1D FEM formulation of Gaudenzi et al. for which a sublaminate approach was used [21]. As an alternative, the layer-wise kinematics proposed by Reddy [5], in which the displacement components are interpolated along $z$ through Lagrange polynomials, was successfully applied by Robbins and Reddy to the Pipes-Pagano problem [22]. Eight-node quadratic plate elements have been used to solve the problem in the $\left(x_{1}, x_{2}\right)$-plane. An $h$ and $p$-refinement along the thickness (i.e., increase of the number of mathematical layers per physical ply or the order of the polynomial expansion) are addressed. The same authors developed in a subsequent work a variable kinematics FEM which permitted them to limit the computationally expensive LW plate elements to the free-edge region, while the inner region was modeled by lower-order (FSDT) elements [23].

Nevertheless, the classical displacement-based method suffers some inherent limitations, in particular the discontinuity of the transverse stress field at the bi-material interface and the approximate satisfaction of the stress-free boundary conditions. So, stress-based equilibrium approaches have been proposed in conjunction with either analytical [24] or numerical FEM-based solutions [25]. Starting from the mixed Hellinger-Reissner (HR) variational principle, Pagano proposed a sound formulation that permits him to express a variationally consistent displacement field starting from only stress assumptions [26]. The mixed HR principle has been employed by Spilker and Chou for developing hybrid-stress FE for the analysis of the Pipes-Pagano problem [27] with the generalized plane strain assumption. The mixed approach of Pagano [26] has been also employed by Nguyen and Caron for formulating LW finite plate elements dedicated to the analysis of free-edge effects [28]. Furthermore, a partially mixed 2D element has been developed by Desai et al. and successfully applied to the free-edge problem [29].

Another way already mentioned above consists in introducing the physical requirements to deduce Zig-zag model. Wu and Chen proposed a higher-order ESL displacement model along with a 3-node finite plate element [30]. This one satisfies a $C^{1}$ weak- continuity condition. Fifth and third-order expansions have been used for the in-plane and transverse displacement components, respectively. The exact satisfaction of the interlaminar continuity condition for the transverse shear stress reduces the unknown functions to 18 . The present refined sinus approach belongs to this family.

Finally, it should be mentioned the family of models based on the Carrera's Unified Formulation employing the Principle of Virtual Displacements and the Reissner's Mixed Variational Theorem. It is one of the only approach which has been assessed on a wide range of test cases [31-33], in particular concerning the local stress concentration occurring in both free edge and localized pressure for highly anisotropic sandwich. Both ESL and LW approaches are addressed.

Based on the sinus theory developed by Vidal and Polit [34] for beams, its generalization to plate has been presented in [35] where a model with 11 parameters is derived. This work has shown accurate results for the modeling of thin to very thick structures of any lamination schemes in the framework of multifield problems with a high convergence rate. The double superposition hypothesis is introduced for the in-plane displacement. The transverse displacement is refined allowing the use of the three-dimensional constitutive law. This is essential for thick structures and multifield problems. All interface continuity and boundary conditions are exactly satisfied for displacement and transverse shear stresses using the Heaviside function. Moreover, transverse shear stresses can be obtained directly from the threedimensional constitutive law.

In the present work, this refined sinus model is extended and assessed with respect to its capacity to capture stress concentrations. In this way, a sinus kinematics including a fourth and third-order expansion is chosen for the in-plane and transverse displacements, respectively. It yields to 16 independent generalized unknowns. Furthermore, a six-node triangular finite element is described and applied to test cases involving local effects. In order to develop a conform, efficient and accurate FE, Argyris and Ganev interpolations are used as in Polit and Touratier [36]. Note that the FE presented in [36] was dedicated to cross ply and symmetric angle ply schemes. These FE approximations are $\mathrm{C}^{1}$ and semi- $\mathrm{C}^{1}$, providing a high convergence rate [35]. Furthermore, since Argyris interpolation is a polynomial of the fifth-order and Ganev interpolation of the fourthorder, the field compatibility for the FE approximations of the transverse shear strains is automatically fulfilled, avoiding the transverse shear locking. So, this FE exhibits no numerical pathology [35].

We now outline the remainder of this article. This new triangular FE with 16 unknown functions is detailed out in the first two sections. Numerical evaluations are subsequently presented. Present numerical results for the Pipes-Pagano problem are first compared with those available in the literature. The study considers symmetric cross-ply and angle-ply laminates. Furthermore, the paper presents results of 3D FEM computations performed with the commercial software ANSYS, against which results from plate models are thoroughly compared. Finally, the modeling of the Meyer-Piening sandwich structure is addressed. In all cases, a comparison with ESL models issued from the Carrera's Unified Formulation is performed. It should be noted that this study is focused on the capabilities of the refined sinus model and not on the performance of the FE which has been already assessed in previous works [36,35].

\section{Description of the plate problem}

\subsection{The governing equations for mechanics}

Let us consider a plate occupying the domain $\mathcal{V}=\Omega \times$ $[-h / 2 \leq z \leq h / 2]$ in a Cartesian coordinate $\left(x_{1}, x_{2}, z\right)$. The plate is 


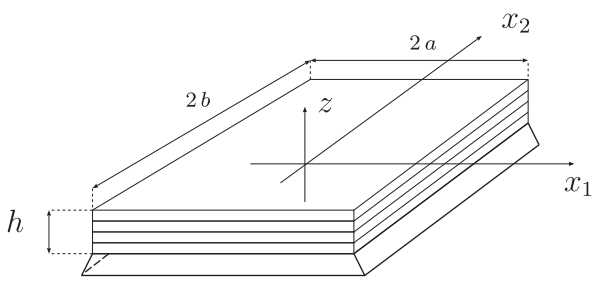

Fig. 1. The laminated plate and coordinate system.

defined by an arbitrary region $\Omega$ in the $\left(x_{1}, x_{2}\right)$ plane, as midplane for $z=0$, and by a constant thickness $h$, see Fig. 1 .

\subsubsection{Constitutive relation}

The plate is assumed to be made of $N C$ perfectly bonded orthotropic layers. Using matrix notation, the three dimensional constitutive law of the $k$ th layer is given by

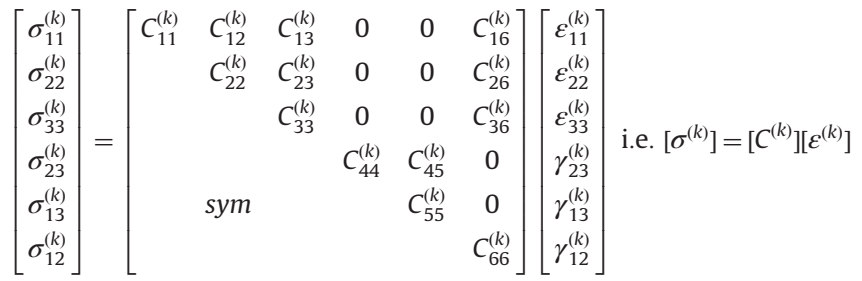

where we denote the stress vector $[\sigma]$, the strain vector $[\varepsilon]$ and $C_{i j}$ the three-dimensional stiffness coefficients with respect to the plate's reference frame $\left(x_{1}, x_{2}, z\right)$.

\subsubsection{The weak form of the boundary value problem}

Using the above matrix notation and for admissible virtual displacement $\vec{u}^{*} \in U^{*}$, the variational principle reads:

find $\vec{u} \in U$ (space of admissible displacements) such that

$$
-\int_{\mathcal{V}}\left[\varepsilon\left(\vec{u}^{*}\right)\right]^{T}[\sigma(\vec{u})] d \mathcal{V}+\int_{\mathcal{V}}\left[u^{*}\right]^{T}[f] d \mathcal{V}+\int_{\partial \mathcal{V}_{F}}\left[u^{*}\right]^{T}[F] d \partial \mathcal{V}=0 \quad \forall \vec{u}^{*} \in U^{*}
$$

where $[f]$ and $[F]$ are the prescribed body and surface forces applied on $\partial \mathcal{V}_{F}$ and $\varepsilon\left(\vec{u}^{*}\right)$ is the virtual strain. $U^{*}$ is the space of admissible virtual displacements.

\subsection{The displacement field for laminated plates}

Based on the sinus function (see [37,38]), a model which takes into account the transverse normal deformation is presented in this section. It is based on

- various works on beams, plates and shells, [37,39] covering the refined theory, and

- the so-called 1,2-3 double-superposition theory of $\mathrm{Li}$ and Liu [40] developed in the sinus approach for plate in Vidal and Polit [35].

Moreover, this refined model (see Vidal and Polit [41]) takes into account the continuity conditions between layers of the laminate for both displacements and transverse shear stresses, and the traction-free conditions on the upper and lower surfaces.

The important feature in this new model is the introduction of (i) a layer refinement with physical meaning, (ii) the transverse normal effect in the framework of plate structures, and (iii) highorder expansion to capture local effects.

For this, the model kinematics is written in terms of Heaviside function according to the following particular form:

$$
\left\{\begin{aligned}
U_{1}\left(x_{1}, x_{2}, z\right)= & u_{0}\left(x_{1}, x_{2}\right)+z u_{1}\left(x_{1}, x_{2}\right)+f(z)\left(w_{0,1}\left(x_{1}, x_{2}\right)+\theta_{2}\left(x_{1}, x_{2}\right)\right) \\
& +z^{3} u_{3}\left(x_{1}, x_{2}\right)+z^{4} u_{4}\left(x_{1}, x_{2}\right) \\
& +\sum_{k=1}^{N C}\left(\bar{u}_{l o c}^{(k)}\left(x_{1}, x_{2}, z\right)+\hat{u}_{l o c}^{(k)}\left(x_{1}, x_{2}, z\right)\right)\left(H\left(z-z_{k}\right)-H\left(z-z_{k+1}\right)\right) \\
U_{2}\left(x_{1}, x_{2}, z\right)= & v_{0}\left(x_{1}, x_{2}\right)+z v_{1}\left(x_{1}, x_{2}\right)+f(z)\left(w_{0,2}\left(x_{1}, x_{2}\right)-\theta_{1}\left(x_{1}, x_{2}\right)\right) \\
& +z^{3} v_{3}\left(x_{1}, x_{2}\right)+z^{4} v_{4}\left(x_{1}, x_{2}\right) \\
& +\sum_{k=1}^{N C}\left(\bar{v}_{l o c}^{(k)}\left(x_{1}, x_{2}, z\right)+\hat{v}_{l o c}^{(k)}\left(x_{1}, x_{2}, z\right)\right)\left(H\left(z-z_{k}\right)-H\left(z-z_{k+1}\right)\right) \\
U_{3}\left(x_{1}, x_{2}, z\right)= & w_{0}\left(x_{1}, x_{2}\right)+z w_{1}\left(x_{1}, x_{2}\right)+z^{2} w_{2}\left(x_{1}, x_{2}\right)+z^{3} w_{3}\left(x_{1}, x_{2}\right)
\end{aligned}\right.
$$

where $H$ is the Heaviside function defined by

$\begin{cases}H\left(z-z_{k}\right)=1 & \text { if } z \geq z_{k} \\ H\left(z-z_{k}\right)=0 & \text { otherwise }\end{cases}$

In Eq. (3), $\left(u_{0}, v_{0}, w_{0}\right)$ are the displacements of a point of the middle surface while $\left(v_{1}, \theta_{1}\right)$ and $\left(u_{1}, \theta_{2}\right)$ are measurements of rotations of the normal transverse fiber around the axis $\left(0, x_{1}\right)$ and $\left(0, x_{2}\right)$, respectively. The higher-order terms are denoted $u_{3}, u_{4}, v_{3}$ and $v_{4}$. The local functions $\bar{u}_{l o c}^{(k)}, \hat{u}_{l o c}^{(k)}$ and $\bar{v}_{l o c}^{(k)}, \hat{v}_{l o c}^{(k)}$ are based on Legendre polynomials and can be written as

$\left\{\begin{array}{l}\left.\bar{u}_{l o c}^{(k)}\left(x_{1}, x_{2}, z\right)=\zeta_{k} u_{31}^{k}\left(x_{1}, x_{2}\right)+-\frac{1}{2}+\frac{3 \zeta_{k}^{2}}{2}\right) u_{32}^{k}\left(x_{1}, x_{2}\right) \\ \left.\hat{u}_{l o c}^{(k)}\left(x_{1}, x_{2}, z\right)=-\frac{3 \zeta_{k}}{2}+\frac{5 \zeta_{k}^{3}}{2}\right) u_{33}^{k}\left(x_{1}, x_{2}\right)\end{array}\right.$

$\left\{\begin{array}{l}\left.\bar{v}_{l o c}^{(k)}\left(x_{1}, x_{2}, z\right)=\zeta_{k} v_{31}^{k}\left(x_{1}, x_{2}\right)+-\frac{1}{2}+\frac{3 \zeta_{k}^{2}}{2}\right) v_{32}^{k}\left(x_{1}, x_{2}\right) \\ \left.\hat{v}_{l o c}^{(k)}\left(x_{1}, x_{2}, z\right)=-\frac{3 \zeta_{k}}{2}+\frac{5 \zeta_{k}^{3}}{2}\right) v_{33}^{k}\left(x_{1}, x_{2}\right)\end{array}\right.$

A non-dimensional coordinate is introduced by $\zeta_{k}=a_{k} z-b_{k}$, with $a_{k}=2 /\left(z_{k+1}-z_{k}\right), b_{k}=\left(z_{k+1}+z_{k}\right) /\left(z_{k+1}-z_{k}\right)$. The coordinate system is precised in Fig. 2.

Finally, the functions $\left(w_{1}, w_{2}, w_{3}\right)$ permit us to have a nonconstant deflection for the transverse fiber and allow us to have nonzero transverse normal strain. Furthermore, the Poisson or thickness locking is avoided assuming an order three for the transverse displacement, see the work of Carrera and Brischetto [42].

In the context of the sinus model, we have

$f(z)=\frac{h}{\pi} \sin \frac{\pi z}{h}$

It must be noticed that the classical homogeneous sinus model [37] can be recovered from Eq. (3) assuming $w_{0,1}=-u_{1}$ $w_{0,2}=-v_{1}$ on the one hand, and neglecting unknown functions

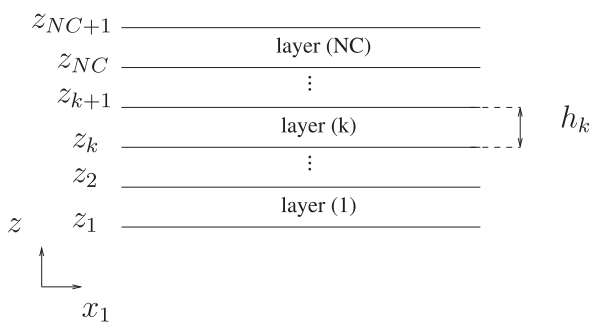

Fig. 2. Transverse coordinate of laminated plate. 
$w_{1}, w_{2}, w_{3}, u_{3}, u_{4}, v_{3}, v_{4}$ and the local thickness functions $\bar{u}_{l o c}^{(k)}, \hat{u}_{l o c}^{(k)}$, $\bar{v}_{l o c}^{(k)}$ and $\hat{v}_{\text {loc }}^{(k)}$, on the other hand. The choice of the sinus function can be justified from the three-dimensional point of view, using the work of Cheng [43]. As it can be seen in Polit and Touratier [36], a sine term appears in the solution of the shear equation (see Eq. (7) in [36]). Therefore, the kinematics proposed can be seen as an approximation of the exact three-dimensional solution. Furthermore, the sine function has an infinite radius of convergence and its Taylor expansion includes not only the third order terms but all the odd terms.

At this stage, $6 \times N C+14$ generalized displacements are included in Eqs. (3)-(5). In the following, the number of unknown parameters is reduced through some relations issued from

- lateral boundary conditions at top and bottom of the plate,

- interlaminar continuity conditions (displacements, transverse shear stresses).

\subsubsection{Continuity conditions and traction-free conditions}

From the displacement field Eq. (3), continuity conditions on displacements and stresses must be imposed. For an interface layer $k \in\{2, \ldots, N C\}$, we have

- the displacement continuity conditions as in Sze et al [44], i.e.:

$$
\begin{array}{r} 
\begin{cases}\bar{u}_{l o c}^{(k)}\left(x_{1}, x_{2}, z_{k}\right)=\bar{u}_{l o c}^{(k-1)}\left(x_{1}, x_{2}, z_{k}\right) & k=2, \ldots, N C \\
\hat{u}_{l o c}^{(k)}\left(x_{1}, x_{2}, z_{k}\right)=\hat{u}_{l o c}^{(k-1)}\left(x_{1}, x_{2}, z_{k}\right) & k=2, \ldots, N C\end{cases} \\
\begin{cases}\bar{v}_{l o c}^{(k)}\left(x_{1}, x_{2}, z_{k}\right)=\bar{v}_{l o c}^{(k-1)}\left(x_{1}, x_{2}, z_{k}\right) & k=2, \ldots, N C \\
\hat{v}_{l o c}^{(k)}\left(x_{1}, x_{2}, z_{k}\right)=\hat{v}_{l o c}^{(k-1)}\left(x_{1}, x_{2}, z_{k}\right) & k=2, \ldots, N C\end{cases}
\end{array}
$$

- the transverse shear stresses continuity conditions between two adjacent layers:

$$
\begin{array}{ll}
\sigma_{13}^{(k)}\left(x_{1}, x_{2}, z_{k}^{+}\right)=\sigma_{13}^{(k-1)}\left(x_{1}, x_{2}, z_{k}^{-}\right) & k=2, \ldots, N C \\
\sigma_{23}^{(k)}\left(x_{1}, x_{2}, z_{k}^{+}\right)=\sigma_{23}^{(k-1)}\left(x_{1}, x_{2}, z_{k}^{-}\right) & k=2, \ldots, N C
\end{array}
$$

This way, $6 \times(N C-1)$ conditions are imposed, which allows us to reduce the number of unknowns to 20 generalized displacements.

Traction-free conditions of the transverse shear stresses on the upper and lower surfaces must also be verified:

$\sigma_{13}^{(1)}\left(x_{1}, x_{2}, z=-\frac{h}{2}\right)=0 \quad$ and $\quad \sigma_{13}^{(\mathrm{NC})}\left(x_{1}, x_{2}, z=\frac{h}{2}\right)=0$

$\sigma_{23}^{(1)}\left(x_{1}, x_{2}, z=-\frac{h}{2}\right)=0 \quad$ and $\quad \sigma_{23}^{(N C)}\left(x_{1}, x_{2}, z=\frac{h}{2}\right)=0$

The number of generalized displacements is reduced to 16 , and is independent of the number of layers: the unknowns are $u_{0}, u_{1}$, $\theta_{2}, u_{3}, u_{4}, v_{0}, v_{1}, \theta_{1}, v_{3}, v_{4}, w_{0}, w_{1}, w_{2}, w_{3}, u_{31}^{1}$ and $v_{31}^{1}$. The resulting model will be denoted SinRef16p.

Note that the constitutive relation Eq. (1) and the compatibility conditions Eq. (11) are used to deduce kinematics relations from Eqs. (9) and (10).

\subsection{The strain field}

From the displacement field Eq. (3) and the physical considerations given in Eqs. (7)-(10), the strain components for a cross-ply composite plate are deduced as

$$
\begin{aligned}
\varepsilon_{11}= & u_{0,1}+z u_{1,1}+\left(f(z)+S_{u \beta}(z)\right)\left(w_{0,11}+\theta_{2,1}\right) \\
& +S_{u \delta}(z) u_{31,1}^{1}+S_{u \lambda}(z) w_{1,11}+S_{u \mu}(z) w_{2,11}+S_{u \zeta}(z) w_{3,11} \\
& +S_{u \eta}(z)\left(w_{0,11}+u_{1,1}\right)+\left(z^{3}+S_{u \gamma}(z)\right) u_{3,1}+\left(z^{4}+S_{u \xi}(z)\right) u_{4,1} \\
\varepsilon_{22}= & v_{0,2}+z v_{1,2}+\left(f(z)+S_{v \beta}(z)\right)\left(w_{0,22}-\theta_{1,2}\right) \\
& +S_{v \delta}(z) v_{31,2}^{1}+S_{v \lambda}(z) w_{1,22}+S_{v \mu}(z) w_{2,22}+S_{v \zeta}(z) w_{3,22} \\
& +S_{v \eta}(z)\left(w_{0,22}+v_{1,2}\right)+\left(z^{3}+S_{v \gamma}(z)\right) v_{3,1}+\left(z^{4}+S_{v \xi}(z)\right) v_{4,1} \\
\varepsilon_{33}= & w_{1}+2 z w_{2}+3 z^{2} w_{3} \\
\gamma_{23}= & \left(f(z)_{, 3}+S_{v \beta}(z)_{, 3}\right)\left(w_{0,2}-\theta_{1}\right)+S_{v \delta}(z)_{, 3} v_{31}^{1}+\left(1+S_{v \eta}(z)_{, 3}\right)\left(w_{0,2}+v_{1}\right) \\
& +\left(3 z^{2}+S_{v \gamma}(z)_{, 3}\right) v_{3}+\left(4 z^{3}+S_{v \xi}(z)_{, 3}\right) v_{4} \\
& +\left(z+S_{v \lambda}(z)_{, 3}\right) w_{1,2}+\left(z^{2}+S_{v \mu}(z)_{, 3}\right) w_{2,2}+\left(z^{3}+S_{v \zeta}(z)_{, 3}\right) w_{3,2} \\
\gamma_{13}= & \left(f(z)_{, 3}+S_{u \beta}(z)_{, 3}\right)\left(w_{0,1}+\theta_{2}\right)+S_{u \delta}(z)_{, 3} u_{31}^{1}+\left(1+S_{u \eta}(z)_{, 3}\right)\left(w_{0,1}+u_{1}\right) \\
& +\left(3 z^{2}+S_{u \gamma}(z)_{, 3}\right) u_{3}+\left(4 z^{3}+S_{u \xi}(z)_{, 3}\right) u_{4} \\
& +\left(z+S_{u \lambda}(z)_{, 3}\right) w_{1,1}+\left(z^{2}+S_{u \mu}(z)_{, 3}\right) w_{2,1}+\left(z^{3}+S_{u \zeta}(z)_{, 3}\right) w_{3,1} \\
= & u_{0,2}+v_{0,1}+z\left(u_{1,2}+v_{1,1}\right)+z^{3}\left(u_{3,2}+v_{3,1}\right) \\
& +z^{4}\left(u_{4,2}+v_{4,1}\right)+\left(f(z)+S_{u \beta}(z)\right)\left(w_{0,12}+\theta_{2,2}\right) \\
& +\left(f(z)+S_{v \beta}(z)\right)\left(w_{0,12}-\theta_{1,1}\right)+S_{u \delta}(z) u_{31,2}^{1}+S_{v \delta}(z) v_{31,1}^{1} \\
& +S_{u \gamma}(z) u_{3,2}+S_{v \gamma}(z) v_{3,1}+S_{u \xi}(z) u_{4,2}+S_{v \xi}(z) v_{4,1} \\
& +\left(S_{u \lambda}(z)+S_{v \lambda}(z)\right) w_{1,12}+\left(S_{u \mu}(z)+S_{v \mu}(z)\right) w_{2,12} \\
& +\left(S_{u \zeta}(z)+S_{v \zeta}(z)\right) w_{3,12} \\
& +S_{u \eta}(z)\left(w_{0,12}+u_{1,2}\right)+S_{v \eta}(z)\left(w_{0,12}+v_{1,1}\right)
\end{aligned}
$$

The expressions of the continuity functions $S_{u \times}(z)$ and $S_{v \times}(z)$ are not detailed here for brevity reason. The process described in [35] can be easily extended for this higher-order kinematics.

\subsection{The matrix expression for displacement and strain}

Matrix notation for the displacement field defined in Eq. (3) can be written using a generalized displacement vector as

$$
\begin{aligned}
& {[u]^{T}=\left[F_{u}(z)\right]\left[\mathcal{E}_{u}\right] \text { with }} \\
& {\left[\mathcal{E}_{u}\right]^{T}=\left[\begin{array}{lllllllllllllll}
u_{0} & \vdots & v_{0} & \vdots & w_{0} & w_{0,1} & w_{0,2} & \vdots & \theta_{1} & \vdots & \theta_{2} & \vdots & u_{1} & \vdots & v_{1}
\end{array}\right.} \\
& u_{3}: v_{3}: u_{4}: v_{4}: w_{1} w_{1,1} w_{1,2}: \\
& \left.\begin{array}{lllllllllll}
w_{2} & w_{2,1} & w_{2,2} & \vdots & w_{3} & w_{3,1} & w_{3,2} & \vdots & u_{31}^{1} & \vdots & v_{31}^{1}
\end{array}\right]
\end{aligned}
$$

$[u]^{T}=\left[\begin{array}{lll}U_{1} & U_{2} & U_{3}\end{array}\right]$

where $\left[F_{u}(z)\right]$ depends on the normal coordinate $z$ and is given in Appendix A.

In a similar manner, from Eq. (11), the following expression can be deduced for the strain field:

$$
\begin{aligned}
& {[\varepsilon]^{T}=\left[F_{\varepsilon}(z)\right]\left[\mathcal{E}_{\varepsilon}\right] \text { with }} \\
& {\left[\mathcal{E}_{\varepsilon}\right]^{T}=\left[\begin{array}{lllllllllllll}
u_{0,1} & u_{0,2} & \vdots & v_{0,1} & v_{0,2} & \vdots & w_{0} & w_{0,1} & w_{0,2} & w_{0,11} & w_{0,12} & w_{0,22} & \vdots
\end{array}\right.} \\
& \begin{array}{lllllllllllll}
\theta_{1} & \theta_{1,1} & \theta_{1,2} & \vdots & \theta_{2} & \theta_{2,1} & \theta_{2,2} & \vdots & u_{1} & u_{1,1} & u_{1,2} & \vdots
\end{array} \\
& \begin{array}{lllllllllll}
v_{1} & v_{1,1} & v_{1,2} & \vdots & u_{3} & u_{3,1} & u_{3,2} & \vdots & v_{3} & v_{3,1} & v_{3,2}
\end{array} \\
& \begin{array}{llllllllllll}
u_{4} & u_{4,1} & u_{4,2} & \vdots & v_{4} & v_{4,1} & v_{4,2} & \vdots & w_{1} & w_{1,1} & w_{1,2}
\end{array} \\
& \begin{array}{lllllll}
w_{1,11} & w_{1,12} & w_{1,22} w_{2} & w_{2,1} & w_{2,2} & w_{2,11} & w_{2,12}
\end{array} \\
& \begin{array}{llllllll}
w_{2,22} & \vdots & w_{3} & w_{3,1} & w_{3,2} & w_{3,11} & w_{3,12} & w_{3,22}
\end{array} \\
& \left.\begin{array}{lllllll}
u_{31}^{1} & u_{31,1}^{1} & u_{31,2}^{1} & \vdots & v_{31}^{1} & v_{31,1}^{1} & v_{31,2}^{1}
\end{array}\right]
\end{aligned}
$$

where $\left[F_{\varepsilon}(z)\right]$ is deduced from Eq. (12) and (A.1) (Appendix A) and is not given for brevity reason.

2.5. The matrix expression of the weak form of the boundary value problem

Using the constitutive relation given in Eq. (1), the matrix expression for strain fields, Eq. (13), the following expressions are 
obtained for the first term of Eq. (2):

$$
\int_{\mathcal{V}}\left[\varepsilon\left(\vec{u}^{*}\right)\right]^{T}[\sigma(\vec{u})] d \mathcal{V}=\int_{\mathcal{V}}\left[\mathcal{E}_{\varepsilon}^{*}\right]^{T}\left[F_{\varepsilon}(z)\right]^{T}[C]\left[F_{\varepsilon}(z)\right]\left[\mathcal{E}_{\varepsilon}\right] d \mathcal{V}
$$

In this expression, the integration throughout the thickness can be explicitly carried out taking into account the stacking sequence of the laminae. The integration with respect to the in-plane domain $\Omega$ is kept:

$$
\begin{gathered}
\int_{\mathcal{V}}\left[\varepsilon\left(\vec{u}^{*}\right)\right]^{T}[\sigma(\vec{u})] d \mathcal{V}=\int_{\Omega}\left[\mathcal{E}_{\varepsilon}^{*}\right]^{T}\left[k_{\varepsilon \varepsilon}\right]\left[\mathcal{E}_{\varepsilon}\right] d \Omega \\
\text { with }\left[k_{\varepsilon \varepsilon}\right]=\int_{-h / 2}^{h / 2}\left[F_{\varepsilon}(z)\right]^{T}[C]\left[F_{\varepsilon}(z)\right] d z
\end{gathered}
$$

where the matrix $\left[k_{\varepsilon \varepsilon}\right]$ can be viewed as the integration over the thickness of the constitutive relations.

Eq. (15) is a good starting point for finite element approximations of the displacement. The generalized strain vector defined by $\left[\mathcal{E}_{\varepsilon}\right]$, see Eq. (13), must be approximated and this will be described in the next section.

For the sake of conciseness, the expression related to the virtual work of the external load is not detailed here.

\section{The finite element approximations: the triangular six-node FE}

This section is dedicated to the finite element approximations of the generalized displacement and strain vectors $\left(\left[\mathcal{E}_{u}\right],\left[\mathcal{E}_{\varepsilon}\right]\right)$ defined in the previous section.

\subsection{Elementary stiffness matrix}

The elementary stiffness matrix $\left[K_{e}\right]$ is deduced from Eq. (15) at the elementary level as

$\int_{\Omega_{e}}\left[\mathcal{E}_{\varepsilon_{e}}^{* h}\right]^{T}\left[k_{\varepsilon \varepsilon}\right]\left[\mathcal{E}_{\varepsilon_{e}}^{h}\right] d \Omega_{e}=\left[Q_{e}^{*}\right]^{T}\left[K_{e}\right]\left[Q_{e}\right]$

where $\Omega_{e}$ refers to one element of the triangulation of the plate reference surface $\Omega \simeq \cup \Omega_{e}$. The superscript $h$ indicates the finite element approximation. $\left[Q_{e}\right]$ is the elementary vector of dofs in global coordinates.

From Eq. (11), the unknowns associated with the deflection $w_{0}^{h}$, $w_{1}^{h}, w_{2}^{h}, w_{3}^{h}$ must be at least $\mathrm{C}^{1}$-continuous functions, while all other generalized functions can be $\mathrm{C}^{0}$-continuous. In order to develop a conform FE approximation, we choose the Argyris interpolation for the transverse displacements and the Ganev interpolation for the other generalized displacements. Since the Argyris interpolation is a polynomial of the fifth order and the Ganev interpolation of the fourth order, we can immediately conclude that the transverse shear locking is avoided as the field compatibility is automatically ensured for the transverse shear strains, see for example [45]. Note that the Argyris interpolation is a $\mathrm{C}^{1} \mathrm{FE}$ approximation, and the Ganev interpolation involves a semi- $\mathrm{C}^{1}$ continuity. Due to the very long expressions for these interpolations, the reader is referred to either the original papers of Argyris et al [46] and Ganev and Dimitrov [47], or to a more recent book of Bernadou [48].

Figs. 3 and 4 show the local degrees of freedom for the approximations of $w_{0}^{h}, w_{1}^{h}, w_{2}^{h}, w_{3}^{h}$ and $u_{\alpha}^{h} ; v_{\alpha}^{h} ; \theta_{\alpha}^{h} ; u_{31}^{1 h}, v_{31}^{1 h}$ respectively. The discrete form of the vector [ $\left.\mathcal{E}_{\varepsilon_{e}}^{h}\right]$ (idem for $\left[\mathcal{E}_{\varepsilon_{e}}^{* h}\right]$ adding an asterisk superscript on the degrees of freedom) may therefore be written as

$\left[\mathcal{E}_{\varepsilon_{e}}^{h}\right]=[\Lambda k]\left[T k_{e}\right]\left[D_{e}\right]\left[Q_{e}\right]$

where $\left[D_{e}\right]$ is a geometric transformation matrix between local and global degrees of freedom. This vector contains the degrees of freedom of the three corner nodes and of the three mid-side nodes (which are not the same):

- for a corner node, we have the following degrees of freedom:

$\begin{array}{cccccc}u_{0} & u_{0,1} & u_{0,2} & v_{0} & v_{0,1} & v_{0,2} \\ w_{0} & w_{0,1} & w_{0,2} & w_{0,11} & w_{0,22} & w_{0,12} \\ \theta_{1} & \theta_{1,1} & \theta_{1,2} & \theta_{2} & \theta_{2,1} & \theta_{2,2} \\ u_{1} & u_{1,1} & u_{1,2} & v_{1} & v_{1,1} & v_{1,2} \\ u_{3} & u_{3,1} & u_{3,2} & v_{3} & v_{3,1} & v_{3,2} \\ u_{4} & u_{4,1} & u_{4,2} & v_{4} & v_{4,1} & v_{4,2} \\ w_{1} & w_{1,1} & w_{1,2} & w_{1,11} & w_{1,22} & w_{1,12} \\ w_{2} & w_{2,1} & w_{2,2} & w_{2,11} & w_{2,22} & w_{2,12} \\ w_{3} & w_{3,1} & w_{3,2} & w_{3,11} & w_{3,22} & w_{3,12} \\ u_{31}^{1} & u_{31,1}^{1} & u_{31,2}^{1} & v_{31}^{1} & v_{31,1}^{1} & v_{31,2}^{1}\end{array}$

- while, for a mid-side node, they are

$\begin{array}{llll}u_{0} & u_{0, n} & v_{0} & v_{0, n} \\ w_{0, n} & & & \\ \theta_{1} & \theta_{1, n} & \theta_{2} & \theta_{2, n} \\ u_{1} & u_{1, n} & v_{1} & v_{1, n} \\ u_{3} & u_{3, n} & v_{3} & v_{3, n} \\ u_{4} & u_{4, n} & v_{4} & v_{4, n} \\ w_{1, n} & w_{2, n} & w_{3, n} & \\ u_{31}^{1} & u_{31, n}^{1} & v_{31}^{1} & v_{31, n}^{1}\end{array}$

where $p_{, n}$ is the derivative with respect to the normal direction of the edge. Finally, in Eq. (17), the matrix $[\Lambda k]$ is expressed as a function of barycentric coordinates, while $\left[T k_{e}\right]$ only contains geometric constants, so that the product $[\Lambda k]\left[T k_{e}\right]$ may be seen as the interpolations with respect to the local degrees of freedom (see Figs. 3 and 4 ) for the components of the vector $\left[\mathcal{E}_{\varepsilon_{e}}^{h}\right]\left(\left[\mathcal{E}_{\varepsilon_{e}}^{* h}\right]\right)$.

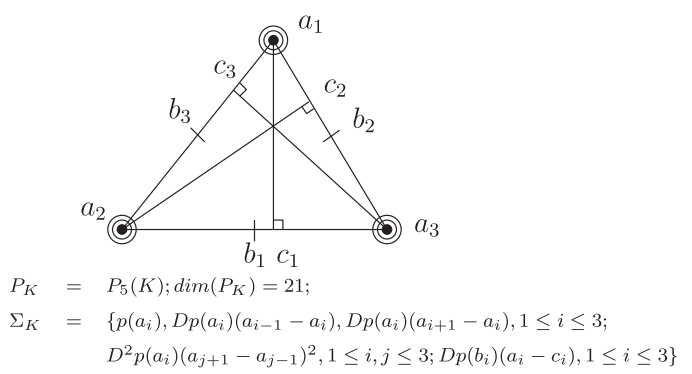

Fig. 3. The set $\Sigma_{K}$ of local dof of a function p for an Argyris triangle.

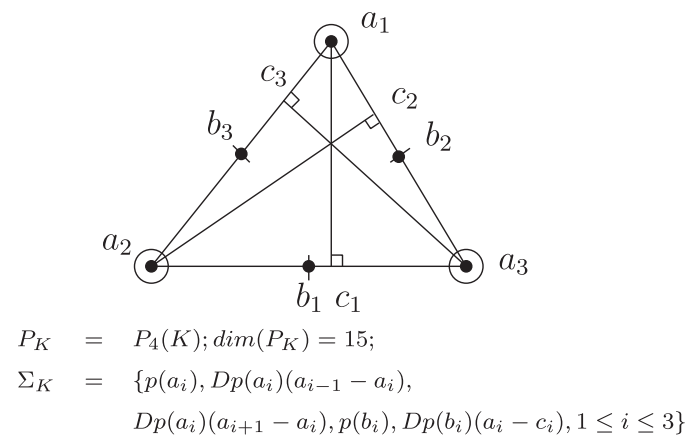

Fig. 4. The set $\Sigma_{K}$ of local dof of a function $\mathrm{p}$ for a Ganev triangle. 
From Eqs. (16) and (17), the elementary stiffness matrix can be written as

$\left[K_{e}\right]=\int_{\Omega_{e}}\left[D_{e}\right]^{T}\left[T k_{e}\right]^{T}[\Lambda k]^{T}\left[k_{\varepsilon \varepsilon}\right][\Lambda k]\left[T k_{e}\right]\left[D_{e}\right] d \Omega_{e}$

The matrices $\left[D_{e}\right],\left[T k_{e}\right],[\Lambda k]$ are detailed in Bernadou [48].

The exact numerical integration rule for the $\left[K_{e}\right]$ matrix is given in Dunavant [49] and requires 16 points for the shear part of this stiffness matrix. The same rule has been used for membrane, bending and refined bending parts.

The formulation to obtain the load vector is classical. It is not precised here for the sake of brevity. For more details, the reader can refer to the work of Polit and Touratier [36].

\subsection{Boundary conditions}

The boundary conditions to be satisfied on the generalized displacements for a simply supported rectangular plate of planeform dimensions $2 \mathrm{a}$ and $2 \mathrm{~b}$ are given by

$$
\begin{aligned}
& \text { - edges } x_{1}=-a \text { and } x_{1}=a \text { for all } x_{2} \in[-b, b] \text { : } \\
& v_{0}^{h}=v_{1}^{h}=v_{3}^{h}=v_{4}^{h}=w_{0}^{h}=\theta_{1}^{h}=w_{1}^{h}=w_{2}^{h}=w_{3}^{h}=v_{31}^{1 h}=0 \\
& \text { - edge } x_{2}=-b \text { and } x_{2}=b \text { for all } x_{1} \in[-a, a] \text { : } \\
& u_{0}^{h}=u_{1}^{h}=u_{3}^{h}=u_{4}^{h}=w_{0}^{h}=\theta_{2}^{h}=w_{1}^{h}=w_{2}^{h}=w_{3}^{h}=u_{31}^{1 h}=0
\end{aligned}
$$

These conditions on the generalized displacements depending on the type of interpolation can be deduced on the dofs using Table 1 . Note that these boundary conditions can be managed automatically using a reference number.

From this table, the generalized displacements concerned by the analytical boundary conditions specified above, and the degrees of freedom for each node (see Eqs. (18) and (19)), it is easy to obtain all the degrees of freedom that must be nil. For a fixed edge, all dofs are nil.

\section{The numerical results}

In this section, several static tests available in open literature are presented for assessing our higher-order refined sinus model and evaluating its capacity to capture steep variation of stresses. Note that the properties of the FE are not studied in the present work. The reader can refer to [35,36] for more details about the excellent properties of this FE concerning accuracy and convergence rate. The results are discussed for both tensile plate with free edge effect and highly anisotropic sandwich structure submitted to a localized loading. The comparisons will involve different refined kinematics models with the same FE approximation based on Argyris-Ganev interpolations [38,45,50]:

SinRef16p present model with 16 unknown functions.

Table 1

Conditions on dofs for the two interpolations.

\begin{tabular}{lllllllll}
\hline Edge & Interpolation & $p$ & $p_{, 1}$ & $p_{, 2}$ & $p_{, n}$ & $p_{, 11}$ & $p_{, 22}$ & $p_{, 12}$ \\
\hline \multirow{2}{*}{$x_{1}=\mathrm{cst}$} & Ganev & 0 & 1 & 0 & 1 & - & - & - \\
& Argyris & 0 & 1 & 0 & 1 & 1 & 0 & 1 \\
$x_{2}=\mathrm{cst}$ & Ganev & 0 & 0 & 1 & 1 & - & - & - \\
& Argyris & 0 & 0 & 1 & 1 & 0 & 1 & 1 \\
\hline
\end{tabular}

0: fixed; 1 : free; -: unavailable.
SinRef11p Refined sinus model with 11 unknown functions, the continuity of the transverse shear stresses is fulfilled (The higher-order functions $u_{3}, u_{4}, v_{3}, v_{4}, w_{3}$ of the SinRef16p are omitted in this model).

Furthermore, reference is also made to the systematic work of Carrera and his "Carrera's Unified Formulation" (CUF), see [51-53]:

ED4 Equivalent Single Layer and Displacement approach, each component is expanded until the fourth order; 15 unknown functions are used in this kinematic.

EDZ4 Equivalent Single Layer and Displacement approach, each component is expanded until the third order and this expansion is extended by the Murakami Zig-Zag function; 15 unknown functions are used in this kinematic.

\subsection{Free-Edge analysis}

The free-edge effects are investigated by referring to the PipesPagano problem illustrated in Fig. 5. According to the common definition of this classical benchmark, the plate width is taken to be $2 b$, the total thickness made of $N C$ identical plies is $2 h=N C h_{k}$ and the ratio $b=4 h$ is employed $[12,18,17,28]$. A uniform axial strain $\epsilon_{0}$ is applied along the $x_{1}$-axis by prescribing end displacements $\bar{u}$ at $x_{1}= \pm a$. All results will be reported in nondimensional form. The uniform traction load induces a constant strain state along the $x_{1}$-axis in the central region of the plate provided the length $a$ is sufficiently large with respect to the perturbed regions next to the pulled edges. Convergence studies performed with 3D Ansys elements, not presented for the sake of

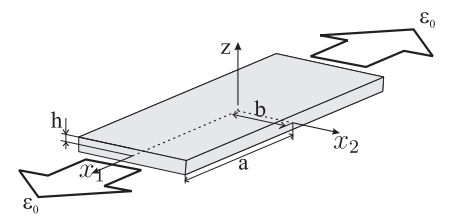

Fig. 5. The Pipes-Pagano problem: composite laminate under uniaxial uniform tensile load.

Table 2

Material properties of the ply (all moduli in $\mathrm{MPa}$ ).

$E_{1}=137900, E_{2}=E_{3}=14480$

$G_{12}=G_{13}=G_{23}=5860$,

$\nu_{12}=\nu_{13}=\nu_{23}=0.21$

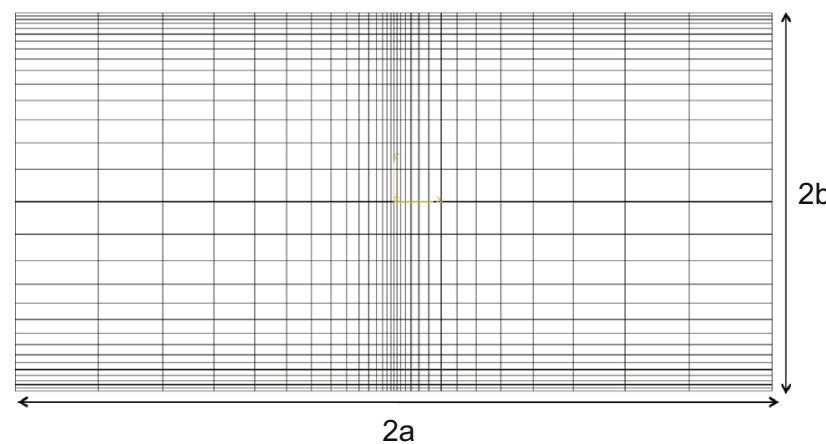

Fig. 6. Mesh employed in the $x_{1} x_{2}$-plane for the 3D and plate simulations. 

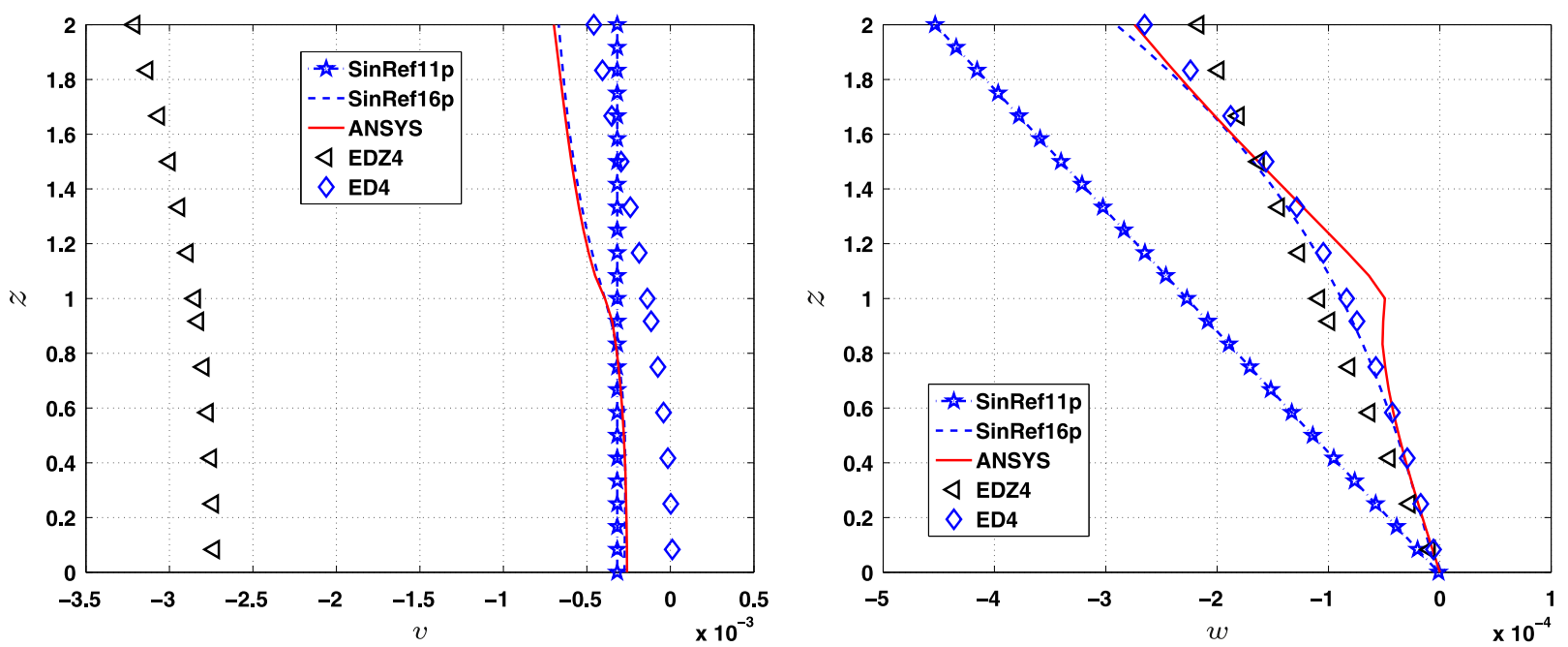

Fig. 7. Distribution of $\bar{v}$ (left) and $\bar{w}$ (right) along the thickness $-\left[0^{\circ} / 90^{\circ}\right]_{S}-$ SinRefc- $11 \mathrm{p} /$ SinRefc-16p.
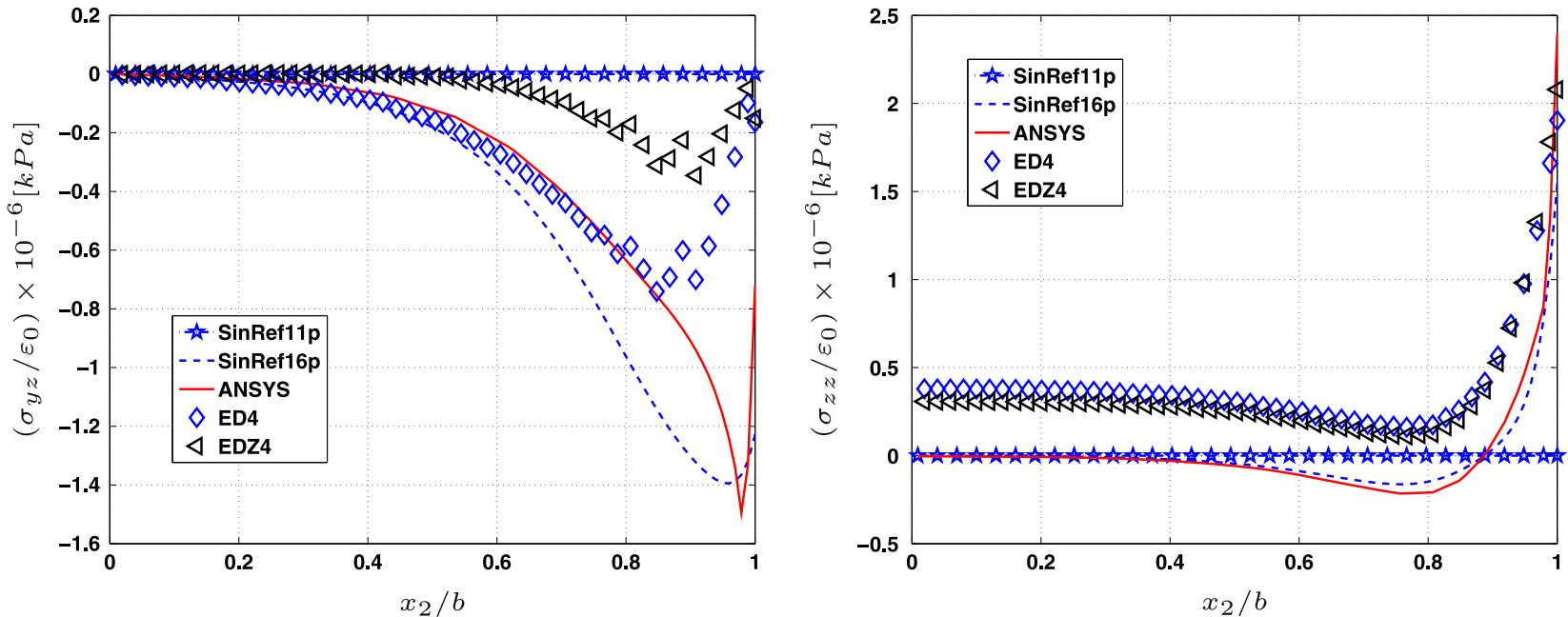

Fig. 8. Interlaminar stresses along $x_{2}$ at the bi-material interface of $\left[0^{\circ} / 90^{\circ}\right]_{S}$ laminate: $\sigma_{y z}$ (left) and $\sigma_{z z}$ (right) - SinRef11p/SinRef16p.
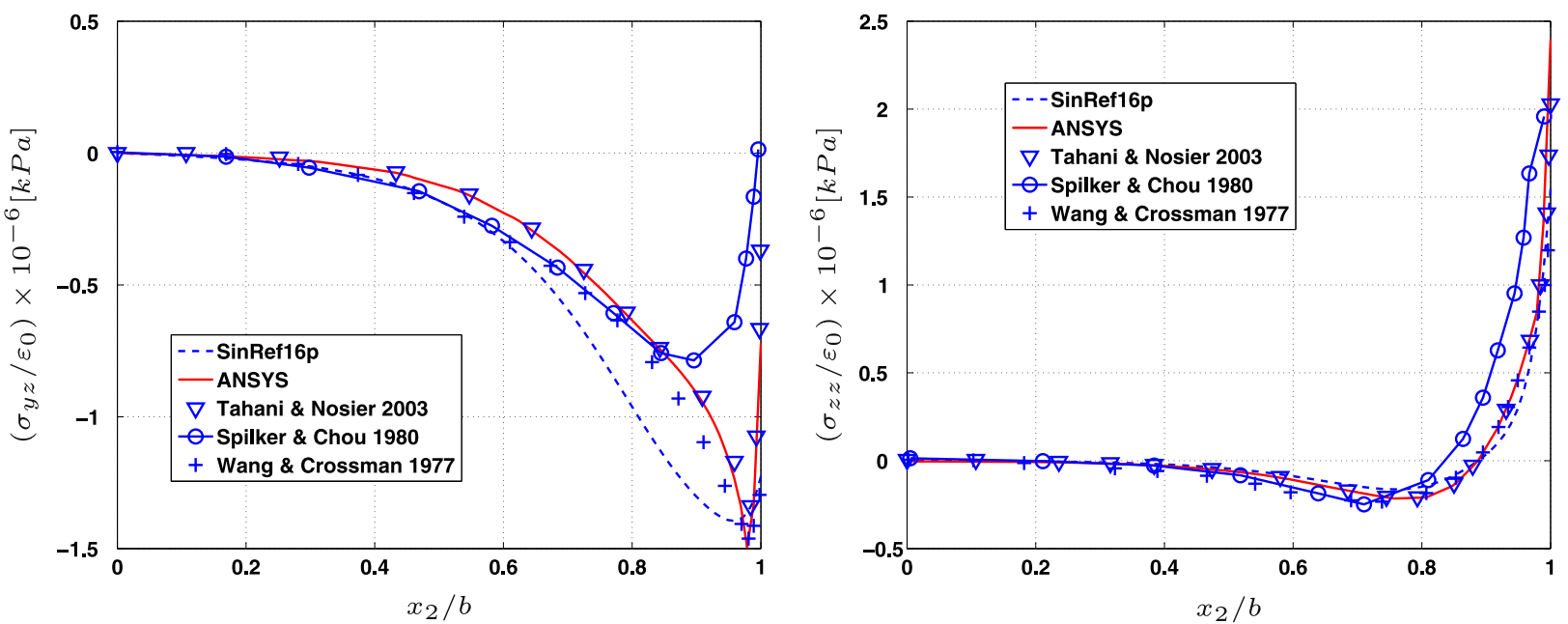

Fig. 9. Interlaminar stresses along $y$ at the bi-material interface of $\left[0^{\circ} / 90^{\circ}\right]_{S}$ laminate: $\sigma_{y z}$ (left) and $\sigma_{z z}$ (right).

conciseness, have shown that $a=2 b=8 h$ provides a sufficient plate length. All plies are CFRP composites with the material properties given in Table 2. These material properties correspond to those employed in previous reference works $[12,18,22,17]$ and permit, hence, a direct comparison of the results.
In the following, the free-edge effects are studied which arise in classical symmetric laminates, namely the cross-ply laminate $\left[0^{\circ}, 90^{\circ}\right]_{S}$ and the angle-ply laminate $\left[ \pm 45^{\circ}\right]_{S}[18,21]$.

A mesh with decreasing element size towards the free edge $x_{2}=b$ is employed in order to capture the steep gradients of the 
response. 3D FEM computations with ANsYs are performed for providing a reference with solid elements (SOLID186). Appropriate spacing ratios are defined for the $3 \mathrm{D}$ mesh which ensure a perfectly cubic shape of the smallest element at the free edge. Several analyses conducted with a different number of elements, not shown for the sake of conciseness, have shown that a mesh with $32 \times 32$ elements in the $x_{1} x_{2}$-plane is adequate, see Fig. 6 . Eight elements per physical layers are used. The same mesh is considered in the $x_{1} x_{2}$-plane for all 2D plate computations. It is to be noted that a coarse mesh $(16 \times 16)$ is sufficient in the analysis involving the Argyris-Ganev interpolations. This particular subject is not addressed in the present work as a singularity behavior occurs in the vicinity of the free edge. Nevertheless, dedicated mesh refinement strategies exist to measure this one as in [54].

First, the results computed with the refined sinus theories, namely SinRef11p and SinRef16p models, are compared with a reference solution computed with Ansys for the cross-ply laminate. In Fig. 7, the in-plane and transverse displacements with respect to the transverse coordinate are presented for the upper half of the plate. The SinRef11p model fails to give accurate transverse displacements whereas the SinRef16p model yields very satisfactory results. As far as the in-plane displacement is concerned, a constant variation through the thickness is obtained for the SinRef11p model which is not the case for the reference solution. The results issued from the SinRef16p model are in very good agreement with the $3 \mathrm{D}$ results. The transverse shear and normal stresses along with the $x_{2}$-axis is also shown in Fig. 8. It is evident that the SinRef11p fails to capture the steepest gradient in the vicinity of the free edge. On the contrary, the SinRef16p model, which includes two and one additional terms for the in-plane and transverse displacements respectively, has capability to represent the strong variation of the stresses. A comparison with two classical ESL models of the CUF family, the ED4 and EDZ4 theories, can also be made. For all these results, the refined Sinus model performs better as these two models. In particular, the displacement $v$ for EDZ4 is far from the 3D model and the maximum value of the transverse shear stress is not well estimated by ED4 and EDZ4. In Fig. 8 (right), the transverse normal stress is not computed in the same way: the Hooke's law is used for the ED4 and EDZ4 models, while the integration of the equilibrium equations is performed for the refined sinus theory. We can say that the steep gradient is captured by the two approaches. Note that the stress in the center of the plate is not well estimated using the constitutive law.
Since ED4 performs better than EDZ4, it can be concluded that in this case, the choice of the order of expansion is more important than the use of the Murakami's zigzag function. It can also be noticed that the introduction of the continuity conditions on the transverse shear stresses improves the accuracy of the results.

For further comparison, the present approach is compared with results available in the literature. The variation of the transverse normal and shear stresses at the bi-material interfaces is shown in Fig. 9. Except for the approach developed by Spilker and Chou [27], all the results are rather close. Note that a quasi-analytical LW approach and a 2D plane strain model in the $x_{1} x_{2}$-plane are carried out in [17] and [18] respectively. These ones yield slightly more accurate results and can handle sharp changes, but our ESL approach with 16 parameters seems to be a good compromise between number of unknowns and efficiency.

Then, a angle-ply laminate $[ \pm 45]_{s}$ is considered. It has been shown that a high gradient at the bi-material interface occurs (see [32]) which makes this test case a very challenging one for 2D plate models. The same comparison as before is performed. First, the distribution of the displacements through the thickness is shown in Fig. 10. The results are quite satisfactory. The SinRef16p is closer to the reference solution than the ED4 model. The same

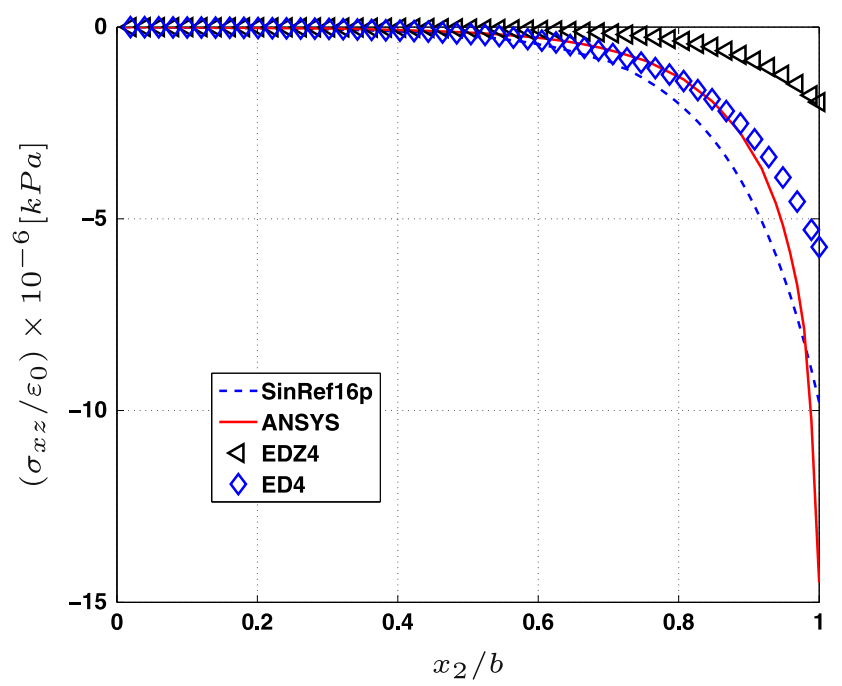

Fig. 11. Interlaminar stresses along $x_{2}$ at the bi-material interface of $\left[45^{\circ} /-45^{\circ}\right]_{s}$ laminate: $\sigma_{x z}-$ SinRef16p.
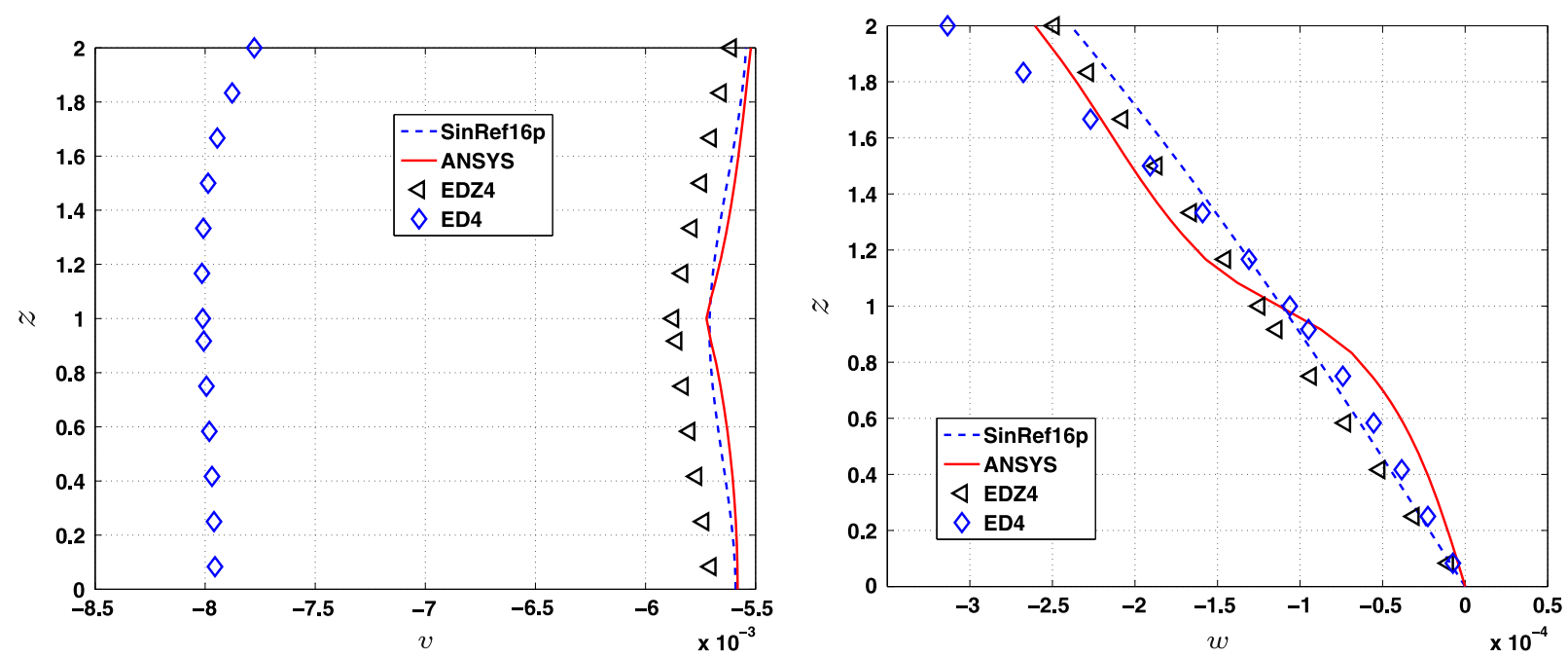

Fig. 10. distribution of $\bar{v}$ (left) and $\bar{w}$ (right) along the thickness $-\left[45^{\circ} /-45^{\circ}\right]_{S}-$ SinRef16p. 

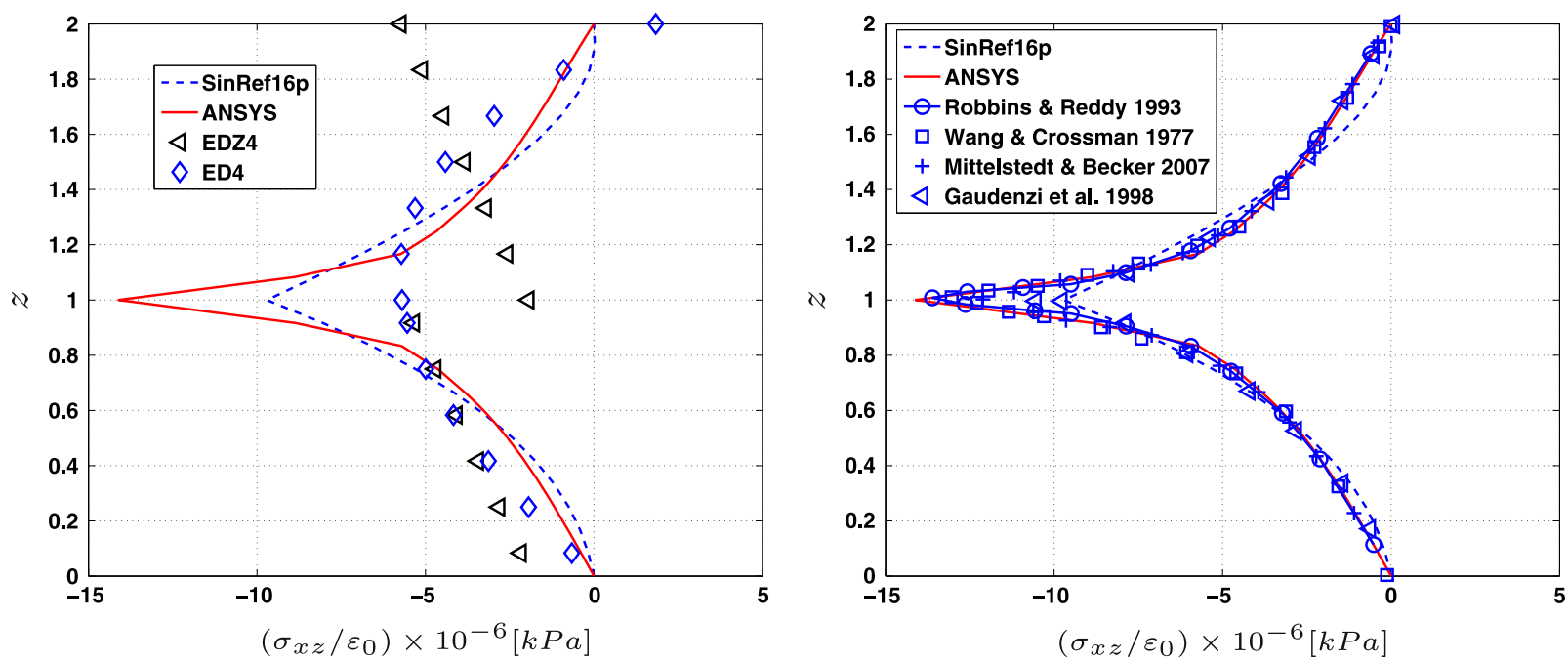

Fig. 12. distribution of $\sigma_{x z}$ along the thickness $-x_{2}=0.99 b-\left[45^{\circ} /-45^{\circ}\right]_{S}-\operatorname{SinRef16p}$.
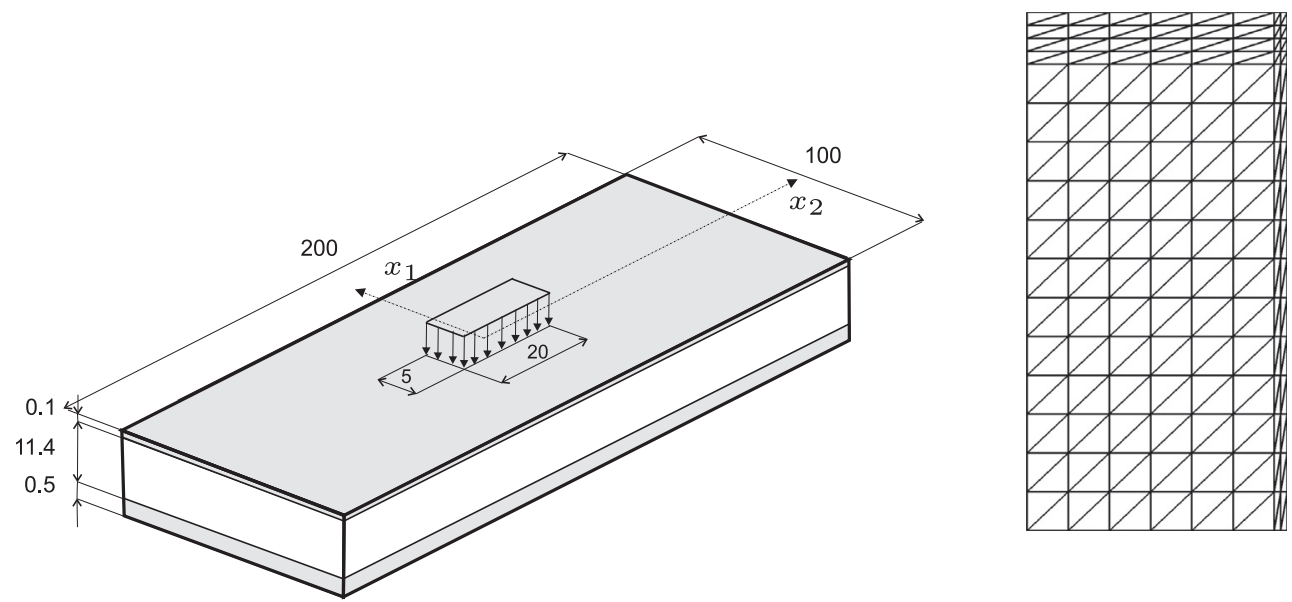

Fig. 13. Meyer-Piening sandwich plate (left) $-N_{x} \times N_{y}=8 \times 16$ mesh of one quarter of the plate (right).

Table 3

Meyer-Piening sandwich: material properties of the ply (all moduli in MPa).

\begin{tabular}{ll}
\hline Faces & Core \\
\hline$E_{1}=70000, E_{2}=71000$ & $E_{1}=E_{2}=3$ \\
$E_{3}=69000$ & $E_{3}=2.8$ \\
$G_{12}=G_{13}=G_{23}=26000$ & $G_{12}=G_{13}=G_{23}=1$ \\
$\nu_{12}=\nu_{13}=\nu_{23}=0.3$ & $\nu_{12}=\nu_{13}=\nu_{23}=0.25$ \\
\hline
\end{tabular}

comment can be made for the variation of the transverse shear stress along the $x_{2}$-axis at the bi-material interface, see Fig. 11. Note that the maximum value near the free edge for the three approaches is under estimated but the accuracy of the SinRef16p model remains better than the two other ones. The distribution of the transverse shear stress through the thickness at $x_{2}=0.99 b$ is also presented in Fig. 12. The high gradient at the bi-material interfaces is rather well captured by the present model even if the maximum value is under estimated. A strong discontinuity appears for the EDZ4 model while the traction-free boundary condition at the top surface is not fulfilled for the ED4 model. Moreover, the concavity of the distribution issued from this latter is not correct. When compared with LW approaches available in the literature ([22,18,16]) shown in Fig. 12 right, the present ESL approach predicts a rather good distribution of $\sigma_{x z}$ through the thickness, even if it fails to give the maximum value. The 1D FE approach using sublaminates from Gaudenzi's work [21] yields rather similar results as our model with a higher number of generalized unknowns. In fact, a 4th and 5th-order expansion is used for the in-plane and transverse displacements respectively.

\subsection{Meyer-Piening sandwich}

The second study deals with a benchmark problem proposed by Meyer-Piening [14]. It involves a simply -supported rectangular sandwich plate submitted to a localized pressure applied on an area of $5 \times 20 \mathrm{~mm}$. The geometry of the sandwich structure is given in Fig. 13. Due to the symmetry, only one quarter of the plate is meshed. The faces have different thicknesses: $h_{1}=0.5 \mathrm{~mm}$ (bottom face), $h_{3}=0.1 \mathrm{~mm}$ (top face). The thickness of the core is $h_{2}=h_{c}=11.4 \mathrm{~mm}$. The material properties are given in Table 3 .

Note that this benchmark involves strong heterogeneities (very different geometric and constitutive properties between core and face) and local stress gradient due to the localized pressure load. For this reason, this test case can be used to well discriminate different 2D theories. The results from the SinRef16p model are compared again with ED4 and EDZ4 models from the CUF (see $[55,31])$. In the following, the LM4 results are considered as the reference ones. This LayerWise model is based on a Reissner's partially Mixed Variational Theorem in which displacement and transverse stress fields vary in each layer according to a 
Table 4

Convergence study - Meyer Piening sandwich.

\begin{tabular}{|c|c|c|c|c|c|}
\hline $\begin{array}{l}N_{x} \times N_{y} \\
N_{x}^{\text {load }} \times N_{y}^{\text {load }}\end{array}$ & $\begin{array}{l}5 \times 10 \\
1 \times 2\end{array}$ & $\begin{array}{l}8 \times 16 \\
2 \times 4\end{array}$ & $\begin{array}{l}10 \times 24 \\
2 \times 8\end{array}$ & $\begin{array}{l}12 \times 36 \\
4 \times 10\end{array}$ & $\begin{array}{l}18 \times 48 \\
4 \times 10\end{array}$ \\
\hline$w(0,0,-h / 2)$ & 2.197 & 2.197 & 2.197 & 2.197 & 2.197 \\
\hline$u(-50,0,-h / 2)$ & 0.011 & 0.011 & 0.011 & 0.011 & 0.011 \\
\hline$\sigma_{11}(0,0, h / 2)$ & -325 & -253 & -255 & -257 & -257 \\
\hline $\operatorname{Max}\left(\sigma_{13}\left(x_{1}, 0,5.9\right)\right)$ & -0.092 & -0.092 & -0.092 & -0.092 & -0.092 \\
\hline
\end{tabular}
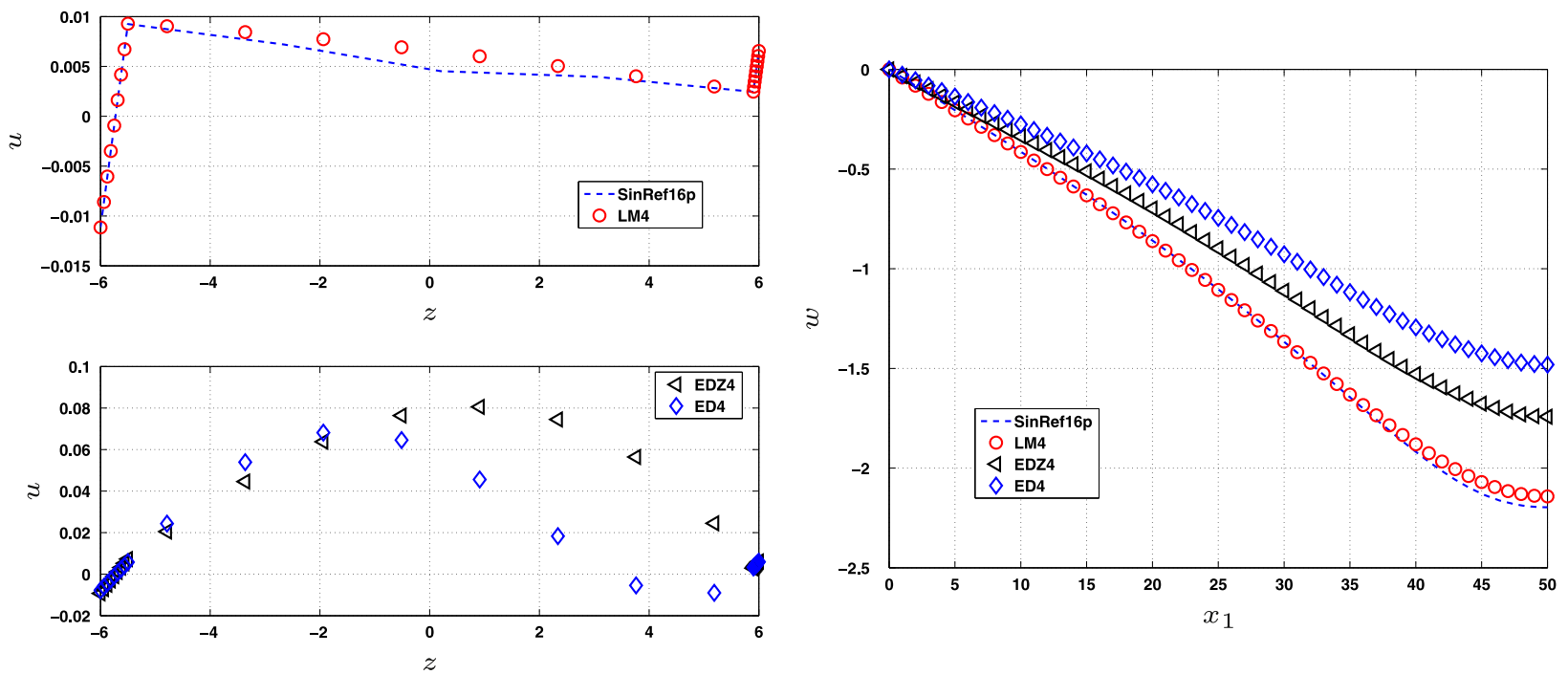

Fig. 14. distribution of $\bar{u}$ (left) along the thickness at $x_{1}=-50, x_{2}=0$, and $\bar{w}$ (right) along the $x_{1}$-axis at $x_{2}=0, z=-h / 2-$ Meyer-Piening test.
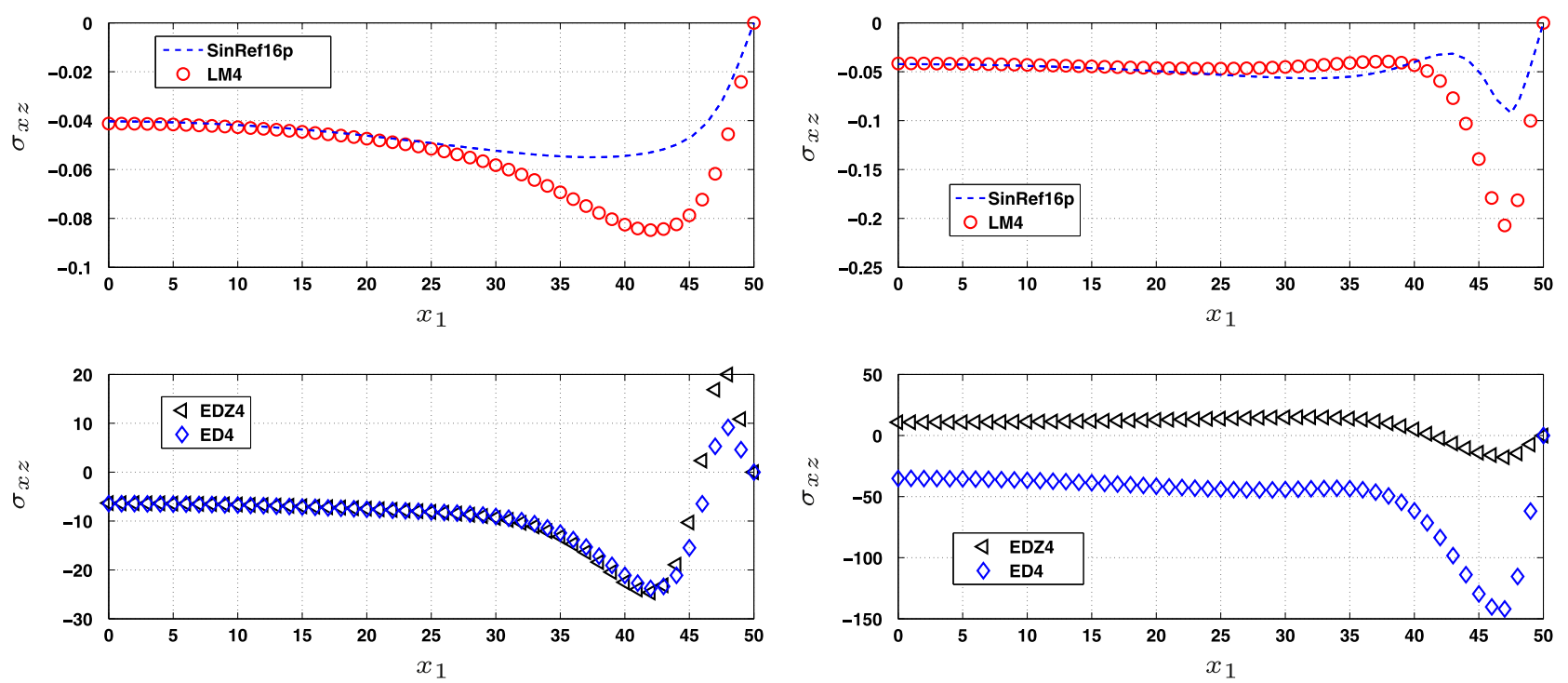

Fig. 15. Interlaminar shear stresses along $x_{1}$-axis at the bottom interface (left) and top interface (right) $-x_{2}=0-$ Meyer-Piening test.

fourth-order polynomial. Note that this severe test case is not frequently addressed in open literature.

Before proceeding to the assessment of the refined sinus model, a convergence study is carried out. The results are summarized in Table 4 for both displacements and stresses. The number of elements under the load is also precised (denoted $N_{x}^{\text {load }} \times N_{y}^{\text {load }}$ ). It can be inferred from this table that the convergence rate is high, especially for the displacements and the maximum value of the transverse shear stress at the top interface. The $8 \times 16$ mesh illustrated in Fig. 13 (right) is sufficient to obtain converged values.
Then, the in-plane and transverse displacements along the $x_{1}$-axis at $z=-h / 2$ are shown in Fig. 14. It can be noticed that the results of the SinRef16p model perform quite well with respect to the reference solution. The zig-zag behavior of the in-plane displacement is well captured whereas the ED4 and EDZ4 results are far from the reference solution (note the different scale of the ordinates). As far as the transverse displacement is concerned, the maximum values of these two theories are underestimated.

The variation of the transverse shear stress at the bottom and top interfaces is presented in Fig. 15. The present refined model 
gives better results as ED4 and EDZ4 approaches. The order of magnitude of the results for these latter models is much higher than the reference values. On the contrary, the accuracy of the refined sinus model is rather good far from the application of the pressure. However, the steepest stress gradient, which is due to the loading discontinuity, is not completely well represented. Thus, it can be inferred from this example that the fulfillment of the continuity of the transverse shear stresses is needed again and improved accuracy of the results when compared with ESL theories involving the same number of generalized unknowns.

\section{Conclusion}

In this paper, a high-order refined sinus model has been presented and assessed with respect to its capability to capture the steep stress gradients. It is an extension of an original 11 parameters plate theory and involves 16 unknown parameters. The employed sinus theory includes a third-order kinematic per layer for the in-plane displacements and a cubic distribution of the transverse displacement. The number of unknowns is independent of the number of layers and all interface and top/bottom boundary conditions are exactly satisfied. Therefore, this approach has a strong physical meaning.

An original FE has been developed based on a conforming FE method and high order FE approximations. This approach has a high convergence rate for displacements and stresses. The field compatibility for transverse shear strains is assured. It is free of numerical illness such as transverse shear and Poisson lockings, oscillation and spurious modes.

The evaluation has been conducted for the free-edge effect in laminated plate and localized load effects in a sandwich one. Comparisons with 3D solutions, results available in open literature and high-order models issued from the CUF are also performed. For some distributions, see Fig. 15, the present approach is able to capture the overall response, but accurate values can be only obtained by high order LW models as LM4. The results show that it is needed to have at least a fourth-order expansion of the in-plane displacements and a cubic one for the transverse deflection to capture the steep mechanical quantities gradient in the vicinity of the free edge or loads. The importance of the continuity of the transverse shear stresses is also emphasized. Finally, the compromise between the computational cost and the accuracy is rather good.

\section{Appendix A. Relation between the generalized displacements}

In Eq. (13), a matrix notation is introduced for the displacement. In this equation, $\left[F_{u}(z)\right]$ is a $3 \times 24$ matrix that depends on the normal coordinate $z$ according to

$$
\begin{aligned}
{\left[F_{u}(z)\right]=} & {\left[\begin{array}{llllllllll}
1 & 0 & 0 & F_{u 4}(z) & 0 & 0 & F_{u 7}(z) & F_{u 8}(z) & 0 & \ldots \\
0 & 1 & 0 & 0 & F_{v 5}(z) & F_{v 6}(z) & 0 & 0 & F_{v 9}(z) & \cdots \\
0 & 0 & 1 & 0 & 0 & 0 & 0 & 0 & 0 & \cdots \\
& F_{u 10}(z) & 0 & F_{u 12}(z) & 0 & 0 & F_{u 15}(z) & 0 & 0 & \ldots \\
0 & F_{v 11}(z) & 0 & F_{v 13}(z) & 0 & 0 & F_{v 16}(z) & 0 & \cdots \\
0 & 0 & 0 & 0 & z & 0 & 0 & z^{2} & \cdots \\
& F_{u 18}(z) & 0 & 0 & F_{u 21}(z) & 0 & & F_{u 23}(z) & 0 \\
0 & F_{v 19}(z) & 0 & 0 & F_{v 22}(z) & 0 & F_{v 24}(z) \\
& 0 & 0 & z^{3} & 0 & 0 & 0 & 0
\end{array}\right] }
\end{aligned}
$$

where

$$
\begin{gathered}
F_{u 4}(z)=f(z)+S_{u \beta}(z)+S_{u \eta}(z) \quad F_{v 5}(z)=f(z)+S_{v \beta}(z)+S_{v \eta}(z) \\
F_{u 7}(z)=f(z)+S_{u \beta}(z) \quad F_{v 6}(z)=-f(z)-S_{v \beta}(z) \\
F_{u 8}(z)=z+S_{u \eta}(z) \quad F_{v 9}(z)=z+S_{v \eta}(z) \\
F_{u 10}(z)=z^{3}+S_{u \gamma}(z) \quad F_{v 11}(z)=z^{3}+S_{v \gamma}(z) \\
F_{u 12}(z)=z^{4}+S_{u \xi}(z) \quad F_{v 13}(z)=z^{4}+S_{v \xi}(z)
\end{gathered}
$$

$$
\begin{array}{ll}
F_{u 15}(z)=S_{u \lambda}(z) & F_{v 16}(z)=S_{v \lambda}(z) \\
F_{u 18}(z)=S_{u \mu}(z) & F_{v 19}(z)=S_{v \mu}(z) \\
F_{u 21}(z)=S_{u \zeta}(z) & F_{v 22}(z)=S_{v \zeta}(z) \\
F_{u 23}(z)=S_{u \delta}(z) & F_{v 24}(z)=S_{v \delta}(z)
\end{array}
$$

and

$\left.\left.S_{\square \times}(z)=\sum_{k=1}^{N C}\left(\zeta_{k} \times_{\square 1}^{k}+-\frac{1}{2}+\frac{3 \zeta_{k}^{2}}{2}\right) \times_{\square 2}^{k}+-\frac{3 \zeta_{k}}{2}+\frac{5 \zeta_{k}^{3}}{2}\right) \times{ }_{\square 3}^{k}\right) \Delta H(k, k+1)$

with $\square=\{u, v\}, \quad \times=\{\beta, \gamma, \delta, \eta, \lambda, \mu, \xi, \zeta\} \quad$ and $\quad \Delta H(k, k+1)=$ $H\left(z-z_{k}\right)-H\left(z-z_{k+1}\right)$.

\section{References}

[1] J. Reddy, A simple higher-order theory for laminated composite plates, J. Appl Mech. ASME 51 (4) (1984) 745-752.

[2] H. Murakami, Laminated composite plate theory with improved in-plane responses, J. Appl. Mech. ASME 53 (1986) 661-666.

[3] N. Pagano, Exact solutions for composite laminates in cylindrical bending, J. Compos. Mater. 3 (1969) 398-411.

[4] J. Reddy, On refined computational models of composite laminates, Int J. Numer. Methods Eng. 27 (1989) 361-382.

[5] J. Reddy, Mechanics of Laminated Composite Plates and Shells-Theory and Analysis, CRC Press Inc.,, Boca Raton, 2004.

[6] R. Kapania, S. Raciti, Recent advances in analysis of laminated beams and plates. Part i: shear effects and buckling, Am. Inst. Aeronaut. Astronaut. J. 27 (1989) 923-934

[7] A. Noor, W. Burton, Assessment of computational models for multilayered composite shells, Appl. Mech. Rev. 43 (4) (1990) 67-97.

[8] E. Carrera, Theories and finite elements for multilayered, anisotropic, composite plates and shells, Arch. Comput. Methods Eng. 9 (2002) 87-140.

[9] J. Reddy, R. Arciniega, Shear deformation plate and shell theories: from stavsky to present, Mech. Adv. Mater. Struct. 11 (2004) 535-582.

[10] Y. Zhang, C. Yang, Recent developments in finite elements analysis for laminated composite plates, Compos. Struct. 88 (2009) 147-157.

[11] O. Allix, C. Dupleix-Couderc, A plate theory as a mean to compute precise $3 \mathrm{~d}$ solutions including edge effects and related issues, in: P. Pimenta (Ed.). New Trends in Thin Structures: Formulation Optimization and Coupled Problems, CISM Courses and Lectures, Springer Vienna, vol. 519, (2010) 1-28.

[12] R.B. Pipes, N.J. Pagano, Interlaminar stresses in composite laminates under uniform axial extension, J. Compos. Mater. 4 (1970) 538-548.

[13] N.J. Pagano, R.B. Pipes, The influence of stacking sequence on laminate strength, J. Compos. Mater. 5 (1971) 50-57.

[14] H.-R. Meyer-Piening, Experiences with exact linear sandwich beam and plate analyses regarding bending, instability and frequency investigations, in: Proceedings of the Fifth International Conference On Sandwich Constructions, September 5-7, vol. I, Zurich, Switzerland, 2000, pp. 37-48.

[15] C. Mittelstedt, W. Becker, Interlaminar stress concentrations in layered structures: Part i-a selective literature survey on the free-edge effect since 1967, J. Compos. Mater. 38 (2004) 1037-1062.

[16] C. Mittelstedt, W. Becker, Free-edge effects in composite laminates, Appl. Mech. Rev. 60 (2007) 217-245.

[17] M. Tahani, A. Nosier, Free edge stress analysis of general cross-ply composite laminates under extension and thermal loading, Compos. Struct. 60 (2003) 91-103.

[18] A.S.D. Wang, F.W. Crossman, Some new results on edgde effect in symmetric composite laminates, J. Compos. Mater. 11 (1977) 92-106.

[19] I.S. Raju, J.H. Crews Jr., Interlaminar stress singularities at a straight free edge in composite laminates, Comput. Struct. 14 (1981) 21-28.

[20] J. Whitcomb, I. Raju, Superposition method for analysis of free-edge stresses J. Compos. Mater. 17 (1983) 492-507.

[21] P. Gaudenzi, A. Mannini, R. Carbonaro, Multi-layer higher-order finite elements for the analysis of free-edge stresses in composite laminates, Int J. Numer. Methods Eng. 41 (1998) 851-873.

[22] D. Robbins, J. Reddy, Modelling of thick composites using a layerwise laminate theory, Int. J. Numer. Methods Eng. 36 (1993) 655-677.

[23] D.H. Robbins Jr., J. Reddy, Variable kinematic modeling of laminated composite plates, Int. J. Numer. Methods Eng. 39 (1996) 2283-2317.

[24] C. Kassapoglou, P. Lagace, An efficient method for the calculation of interlaminar stresses in composite materials, J. Appl. Mech. ASME 53 (1986) $744-750$.

[25] E. Rybicki, Approximate three-dimensional solutions for symmetric laminates under inplane loading, J. Compos. Mater. 5 (1971) 354-360.

[26] N.J. Pagano, Stress fields in composite laminates, Int. J. Solids Struct. 14 (1978) 385-400.

[27] R.L. Spilker, S.C. Chou, Edge effects in symmetric composite laminates: importance of satisfying the traction-free-edge condition, J. Compos. Mater. 14 (1980) 2-20.

[28] V.-T. Nguyen, J.-F. Caron, A new finite element for free edge effect analysis in laminated composites, Comput. Struct. 84 (2006) 1538-1546. 
[29] G. Ramtekkar, Y. Desai, On free-edge effect and onset of delamination in FRPC laminates using mixed finite element model, J. Reinf. Plast. Compos. 28 (2009) 317-341.

[30] W. Zhen, C. Wanji, A higher-order displacement model for stress concentration problems in general lamination configurations, Mater. Des. 30 (2009) $1458-1467$.

[31] E. Carrera, Theories and finite elements for multilayered plates and shells: a unified compact formulation with numerical assessment and benchmarking, Appl. Mech. Rev. 10 (3) (2003) 215-296.

[32] M. D'Ottavio, P. Vidal, E. Valot, O. Polit, Assessment of plate theories for freeedge effects, Compos. B: Eng. J. 48 (2013) 111-121.

[33] N. Thai, M. D'Ottavio, J.-F. Caron, Bending analysis of laminated and sandwich plates using a layer-wise stress model, Compos. Struct. 96 (2013) 135-142.

[34] P. Vidal, O. Polit, A refined sine-based finite element with transverse norma deformation for the analysis of laminated beams under thermomechanical loads, J. Mech. Mater. Struct. 4 (6) (2009) 1127-1155.

[35] P. Vidal, O. Polit, A refined sinus plate finite element for laminated and sandwich structures under mechanical and thermomechanical loads, Comput. Methods Appl. Mech. Eng. 253 (2013) 396-412.

[36] O. Polit, M. Touratier, High order triangular sandwich plate finite element for linear and nonlinear analyses, Comput. Methods Appl. Mech. Eng. 185 (2000) 305-324.

[37] M. Touratier, An efficient standard plate theory, Int. J. Eng. Sci. 29 (1991) 901-916.

[38] F. Dau, O. Polit, M. Touratier, $C^{1}$ plate and shell finite elements for geometrically nonlinear analysis of multilayered structures, Comput. Struct. 84 (2006) 1264-1274.

[39] M. Touratier, A generalization of shear deformation theories for axisymmetric multilayered shells, Int. J. Solids Struct. 29 (1992) 1379-1399.

[40] X. Li, D. Liu, Generalized laminate theories based on double superposition hypothesis, Int. J. Numer. Methods Eng. 40 (1997) 1197-1212.

[41] P. Vidal, O. Polit, A family of sinus finite elements for the analysis of rectangular laminated beams, Compos. Struct. 84 (2008) 56-72. http://dx doi.org/10.1016/j.compstruct.2007.06.009.
[42] E. Carrera, S. Brischetto, Analysis of thickness locking in classical, refined and mixed multilayered plate theories, Compos. Struct. 82 (2008) 549-562.

[43] S. Cheng, Elasticity theory of plates and a refined theory, J. Appl. Mech. ASME 46 (1979) 644-650.

[44] K. Sze, R. Chen, Y Cheung, Finite element model with continuous transverse shear stress for composite laminates in cylindrical bending, Finite Elem. Anal. Des. 31 (1998) 153-164.

[45] O. Polit, M. Touratier, P. Lory, A new eight-node quadrilateral shear-bending plate finite element, Int. J. Numer. Methods Eng. 37 (1994) 387-411.

[46] J. Argyris, I. Fried, D. Scharpf, The tuba family of plate elements for the matrix displacement method, Aero. J. Royal Aeronaut. Soc. 72 (1968) 701-709.

[47] H. Ganev, T. Dimitrov, Calculation of arch dams as a shell using an ibm-370 computer and curved finite elements, in: Theory of shells, North-Holland, Amsterdam, 1980, pp. 691-696.

[48] M. Bernadou, Finite Elem. Methods Thin Shell Probl., John Wiley et Sons, New York, 1996

[49] D. Dunavant, Hight degree efficient symmetrical gaussian quadrature rules for the triangle, Int. J. Numer. Methods Eng. 21 (1985) 1129-1148.

[50] O. Polit, M. Touratier, A multilayered/sandwich triangular finite element applied to linear and nonlinear analysis, Compos. Struct. 58 (2002) 121-128.

[51] E Carrera, Developments, ideas and evaluations based upon the reissner's mixed theorem in the modeling of multilayered plates and shells, Appl. Mech. Rev. 54 (2001) 301-329.

[52] E. Carrera, Historical review of zig-zag theories for multilayered plates and shells, Appl. Mech. Rev. 56 (3) (2003) 287-308.

[53] M. D'Ottavio, D. Ballhause, T. Wallmersperger, B. Kröplin, Considerations on higher-order finite elements for multilayered plates based on a unified formulation, Comput. Struct. 84 (2006) 1222-1235.

[54] L. Gu, T. Belytschko, A numerical study of stress singularities in a two-material wedge, Int. J. Solids Struct. 31 (1994) 865-889.

[55] E. Carrera, L. Demasi, Two benchmarks to assess two-dimensional theories of sandwich, composite plates, Am. Inst. Aeronaut. Astronaut. J. 41 (7) (2003) 1356-1362. 